\title{
YEVGENIA KONONENKO’S DETECTIVES
}

\section{Tkachenko T. I.}

\section{INTRODUCTION}

Yevgeniya Kononenko's prose works illustrate today's realities. The writer analyzes the spiritual atmosphere of the modern society, involving the issues of culture and psychology of Ukrainian society. This problem covers all areas of human life, which influences the organization of artistic text: works "Imitation" and "Betrayal" are characterized by meaningful multi-levelness, represent the novel synthesis, which combines criminal, social, psychological and philosophical genres of the novel.

The American writer E.Po. is recognized as the founder of the detective genre. At the end of XIX - in the first half of XX century the criminal story was popularized by the English - A. Conan Doyle and Agatha Christie, the demand for detectives which exceeded the publication of Shakespeare's works. Most literary critics note that in Ukraine attention to criminal histories arose in the 1920s (art texts by M. Jogansen, Y. Smolych). This view can be refuted. It is appropriate to see the beginning of the detective tradition in Ukrainian writing in the first literary interpretation of the crime (by the way, based on real facts), which was presented by the woman in 1902 with the story "Earth". That is why YevgeniyaKononenko should be considered as the heir of not only Agatha Christie but also Olga Kobylyanska. Subsequently, the emergence of criminal stories, where the crime reveals an observant and intelligent character, who becomes the main character of a number of stories. The role of a Soviet detective is often featured by a police representative, as the police in the USSR worked exclusively on state structures (for example, "Justice is my craft” by V. Kashyn).

Detective intrigue contributes to the development of the plot in the artistic text. The writer uses it to create a mystery effect. Intrigue adjusts the pace of the unfolding events, provides readers with activity in the search for the puzzle of the detective rebus. Criminal history is a story frame.

Novels "Imitation" and "Betrayal" have typical detective components: the offender, the victim, the spur. This triangle determines the range of thoughts and actions of the other characters. But actualization 
of contemporary social problems, retrospective analysis of the past influence on the formation of generations of the Ukrainian nation, exhaustive individual characterization of images.

\section{Features of the Image of a Female Detective}

In the novels "Imitation" and "Betrayal" there is a constant figure Larysa Lavrynenko. The writer gives the role of a spinster to a woman. If Western authors "deprive" their heroes of their families (husband, children, wife), then Yevgeniya Kononenko emphasizes that personal relationships, an intimate component, are dominant in the life of any person. Unlike their previous counterparts (Sherlock Holmes, Nat Pinkerton, Miss Marple, Hercule Poirot) and contemporary colleagues (Nastya Kamenskaya, Yevlampiya Romanov, Dasha Vasilyeva), Larysa Lavrynenko successfully combines the work of a detective with everyday troubles. She is an ordinary woman: raising a teenage son, caring for a grumpy mother, working to provide for a family, because the missing man, an American worker, is not worth the hope. Focus solely on Lavrynenko's murder cases do not allow the realities of today. A woman lacks free time to solve a crime. A. Conan Doyle and Agatha Christie avoid the meticulous analysis of their heroes' daily troubles over material problems to emphasize their uniqueness, unlike ordinary people. Sherlock Holmes is defined as a "perfect machine" Instead, Yevgeniya Kononenko emphasizes on the authenticity of Larysa's image, encompasses all the components of her life, highlighting the real conditions of existence in the modern world. Ms. Lavrynenko investigates a murder if she is "forced" to do so, ie when the crime concerns a woman's acquaintance. Detective work is one of the components of her full-fledged human existence that Larysa tries to live with. For her, the disclosure of a crime is a way of activating the mind. If Mr. Holmes, Miss Marple, and even Andrew ("The Key" by V. Shklyar) seek to solve the mystery because of their interest in the case and enjoy the process of disclosing the crime because of their personal interest in a particular criminal event, then Ms. Lavrynenko investigates the murder by controlling and therefore a certain obligation to the dead. Playing the stages of amateur search for the perpetrator Larysa, the author emphasizes her own feminine qualities, which helps to reject false conclusions and to find the truth - female intuition. Agatha Christie came close to revealing the essence of the phenomenon, though she did not name it. Larysa Lavrynenko may ignore obvious facts, but instead relies on largely unmotivated unconscious 
premonitions that do not appear anomalous at the final retrospective view of events. She draws attention first of all to the inner essence of man. Feminine logic and intuition work together, complementing each other, representing the synthesis of the abstract (sense) and the concrete (facts). Often, their properties in criminal proceedings are more effective than hypotheses that arise in the process of causation. Using feminine logic, wisdom, intuition, a female spit is able to find out the motives of the crime by noticing the change in the finale in an amateur performance; verify existing assumptions through a hands-on experiment with a lifethreatening role; reconstruct the sequence of events by observing the emotions of crime participants; to find the perpetrator, remembering the victim's lost gloves.

The main source of truth and the arena of action of women's logic and intuition is communication, which helps both the underdog and the offender. It is in a private face-to-face conversation that you can get the information you need, notice the person's reaction to a specific name, thing, situation: body movement, look, gesture or random word indicators of the interlocutors, their subjective assessment of what it is said. Even the most talented actor is able to make mistakes, because controlling yourself every second is extremely difficult.

Larysa adapts to the interlocutor, listens and asks, uses the information provided about the person in search of the solution, finds the right links to find the details that later help to solve the murder. A woman-detective is interested in people, not things. Nat Pinkerton and Sherlock Holmes are convinced of their infallibility. Lavrynenko is not afraid to make mistakes, so she checks doubts, weighs every word in order to prevent further tragedies that may lead to the exposure of the perpetrator.

The choice of sex of the detective is determined by his/her inherent abilities. Men choose the deductive method with the means of analytic masculine logic, which is based on external factors and works solely through causation. The undeniable (innate) superiority of the female detective in feminine logic and intuition, which allows suggesting anomalous (in the opinion of a male spy, logical and absurd) hypothesis that can answer any questions about crime.Women are the direct victims. Their death is a mystery to the environment. Larysa investigates the psychology of the slain Mariyana and Veronica. She draws on her own knowledge, the source of which is the relationship between her and the dead ${ }^{1}$.

\footnotetext{
${ }^{1}$ Біла А. Сфери інобуття у прозі Євгенії Кононенко // Березіль, 2001. - № 3-4. Ст. 56.
} 
The author imbues the whole work with prompts. The reader is initially introduced to the offender by the invisible mention of him in the conversation of the participants in the events. But then the frequency of appearance of this figure increases, which causes the attentive reader, like the female detective, to look more carefully at the character. The gradual mosaic drawing of a complete psychological portrait of a particular artistic image, thanks to retrospective, actions and thoughts, introspection, commentary, allows the recipient to make his own assumptions.

Through the images of victims and murderers, Yevgeniya Kononenko points to the difference between the representatives of the feminine and masculine sex in the motivation, intent and realization of the crime. Men commit a crime of affection, they are unable to control, to restrain their momentary emotions, as evidenced not only by the murder, but also by the facts of domestic violence (behavior of Dmytro Stebelko, Ivan Rayevsky). Instead, thieves carefully plan actions, select words and expressions of feelings to easily manipulate people. The innate ability to sense the deepest disturbances of the human soul allows the killer to prevent exposure by controlling the actions of the environment. In this way, the author refutes the idea of emotional dominance in women and the benefits of rationalism in the masculine world. The vicious cruelty and hidden fury of the thief exceed the intentions of the thief. Women justify criminal acts by feelings (love, hate, despair, fear), men - by the demands of society (money, status). It is worth noting that the writer emphasizes the plausibility of events when ordinary people become criminals through external or internal conflicts that are characteristic of many The American researcher R.Kania calls the defining feature of women's detective stories - the projection of personal conflict into a wider social conflict. Agatha Christie detectives recreate the morals and way of life of England in the first half of the XXth century, and the novels of Yevgeniya Kononenko represent Ukraine at the beginning of the XXIst century. Through the characters of the artistic texts "Imitation" and "Betrayal" the writer embodies the author's vision of the country, the spiritual and material aspect of life of Ukrainians.

Investigating the psychological level of works, it is appropriate to pay attention to the fact that the dominant issue of Kononenko's novels is gender issues. Each person involved in the crime reflects a specific type of behavior of a female or male representative. The author emphasizes two priority factors that shape the individual - national (innate) and social (acquired). Therefore, ethnogenetic memory and socialization, guided by 
moral and ideological education, determine the world outlook of man. A typical consequence of the extreme masculinization of a woman is seen in the image of Mariya Stebelko. Career ambitions have treated autocracy as the only possible form of organizing one's family. Drawing on the image of Mariya, Kononenko uses a retrospective. The dehumanization of society has distorted the image of the mother-woman. Mariya takes on the position of Director of Forestry. At the same time, Ms. Stebelko's fanaticism in the work absorbs feelings of love, love and respect.

However, the image of Mariya Stebelko reflects the coexistence of two opposing but interconnected constituents in man - artificial, externally (Soviet) and natural, ethnic (Ukrainian). The writer emphasized the role of ethnogenetic memory, which is rooted in the personality and actualized in certain situations, defines the life position, behavior, principles of the individual, correlating own outlook. Mariya retained, albeit at a subconscious level, ethnic relics in the belief in unclean power, in the rejection of betrayal, religious foundations in punishment for evil deeds. The author embodies the synthesis of the traits born and acquires by the Ukrainians throughout their history.

In the image of Tetiana Mayakina (Murchenko), a certain psychoand socio-type of a person of pre-Ukrainian society is represented. The character traits should be interpreted as a borderline expression of matriarchy: deliberately severed communication between the child and the father, permissiveness, absolute confidence in their correctness. Mother's love turns private property into the most valuable person. There is a noticeable intertextual cut - allusions to Lesya Ukrainka's "Blue Rose” and Olga Kobylyanska’s “Wolf”.

Complex of unrealized wife, beloved, destroys Mrs. Murchenko's consciousness, mother and the professional. The murder of Veronica Rayevskaya-Stebelko becomes a manifestation of the jealousy of a mother-in-law. Having learned to be only a caretaker, Mayakina cannot but manipulate someone, justifying her actions with sincere concern for the welfare and happiness of the object of all her worries. The woman rejoices in the eternal infant-alphonse Adrian Borych, who has returned for financial compensation to satisfy her distorted maternal instinct.

Opposition Tetiana, as the embodiment of the extremes of the matriarchy, is the image of Dmytro Stebelko, which reproduces the type of person formed by patriarchal society. Men's perceptions are governed by gender stereotypes. The constant need to protect someone is in fact a form of domination, a way of asserting their importance. Animals and 
then humans become the objects of a kind of domination. The husband's attitude to the cat and his wife is the same. Material Dmytro defines the pledge of happiness of the family. The privileged status of "breadwinner" allows a man to demand unpardonable obedience, without burdening himself with uninteresting conversations with a woman. Dmytro controls every step of Veronica: double morality and double standards are the natural consequence of a functioning slave-master model. This model is most distorted in the image of Ivan Rayevsky, which is also aided by the distorted system of the Soviet totalitarian regime, where the hero of war becomes the authority of the criminal gang. The permissiveness of Rayevsky, who "feared neither the police nor God", is projected into Stebelko's figure. Dmytro ignores Veronica's attempts to rid himself of the role of a grateful victim who can turn a slave and master into partners. The husband's attitude to his wife is identical to the actions of her offender. Ivan Rayevsky secures his presidency in the family and gang of criminals through physical violence, DmytroStebelko- moral humiliation. The father choked the little Veronica with his hands, and the husband with the mention of his "moral sacrifices" in favor of his wife, daughter. The limitless power of the master is directly proportional to the destruction of the slave's personality and the degradation of the master. Therefore, the loss of leadership in the family frightens a man to whom society has given the right to the superiority of feminine gender from birth. The established system of behavior for men causes Dmytro's internal breaking. He is trapped in the common gender stereotypes in society. The complex of "strong" man Dmytro justifies the rejection of "related”, but not immediately profitable, work. After all, Ms. Rayevska did not require anything. Veronica's apparent betrayal culminates in the couple's relationship and the beginning of the woman's self-identification. Wife's confession caused an explosion of unrealized man's emotions accumulated over the years: the use of physical superiority by a man is the only means to protect his status. The blow to Dmytro Stebelko in the face of his wife testified to the mental and sensual degradation of a man who regressed to the level of an animal. Stereotype dictates maintaining a dominant role in all circumstances, using violence when "property" persistently seeks control: a "strong" man is asserted with the help of a "weak" woman; the triumph of his power is possible only through the humiliation and oppression of her personality. But in such a situation there are no winners: the master and the slave are always dependent on each other; it is impossible to become free. When the wife begins to study 
and work for the sake of independence, the husband interprets these actions as crime. The real victim of the prison of stereotypes is Dmytro, who, in an effort to satisfy social demands, loses himself.

Instead, the image of his wife reproduced the path of a man who dared and was able to overcome patterns, which ensured her development to the level of personality. By means of a retrospective display of the vicissitudes, the author illuminates the process of graduation of the individual. Initially, Yevgeniya Kononenko emphasizes on the conscious infantile nature of a woman. Married and giving birth to a daughter of seventeen, Veronica stopped her search for identity. Wishing to remain a child forever, the woman deprived herself of the right to live outside the apartment, becoming the usual next item of interior. Veronica represents a woman who wants and is able to represent herself in all functions (mother, wife, sweetheart, friend, specialist), therefore, proving her right to be a complete person ${ }^{2}$.

With the help of artistic images (Dmytro, Veronica, Mariya, Tetiana), the author emphasizes that only an individual who understands the weight of two components of being (intimate and professional sphere) can get rid of complexes, artificially created and imposed templates without harming other people and retaining their own self. Yevgeniya Kononenko highlights the crippling influence of gender stereotypes when the ideological regulation of human life causes a distortion of the inner human being, shows personal crisis in social projection.

In the characters, their feelings and actions, the writer not only reproduces a unique personality. The author portrays them as representatives of a certain ethnic group through the markers of their outlook, seeking to achieve extreme drama in manifestations of the main features of the Ukrainian mentality. Kononenko interprets national character as a peculiar form of existence of worldview and consciousness of the nation. It draws a retrospective to emphasize the conditions of character formation. According to the psychological portrait of a person, the author distinguishes the constant features of Ukrainians.

Emotionalism is capable of "paralyzing" a person. The most striking manifestation of this innate trait is observed in the image of Mariyana Hrypovych. A 21st century career woman is stubbornly trying to acquire the image of a pragmatic European. The author points to the discordance between Mrs. Hrypovych's concept of a "talent-centric universe", the focus of which is God and nature, which contradicts her claim to the universal

\footnotetext{
${ }^{2}$ Кононенко Є. Імітація. Львів: Кальварія, 2001. Ст. 160.
} 
monetary equivalent. Mariyana cannot overcome the psychological dominant of national character, she is not capable of constantly lying to herself. She risks considerable money, prestigious work, reputation to please her lover. The woman admitted her defeat when she tried to reject, to destroy the innate privilege of feeling. The insights cost Ms. Hrypovych a deadly price, following a fatal sentence of fate. Yevgeniya Kononenko embodies the complete manifestation of cordocentrism in the most categorical way and in the most paradoxical situation: becoming the main representative of the "philosophy of the heart", this woman immediately finds herself on a train track. Mariyan's attitude to "ordinary" people, in particular to Yurko's feelings, testifies to the presence in the Ukrainian mentality of a component that was thoroughly researched by O. Kulchytskyi and I. Mirchuk - excessive individualism, which implies neglect, rejection of the thoughts of other, established requirements, norms, satisfy their whims. An open demonstration of "contempt for the cattle", a lack of respect for the "unelected" is the cause of the deliberate crime of a deliberately abused child.

Individualism becomes partly the basis of another marker of mentality - male infantilism. The origins of this thought are pertinent to see from the eighteenth century, because, according to historical facts, the Ukrainian spouses are characterized by parity relations (the "furnace" rite, the marriage promise of mutual assistance and respect), at least until the final subordination to the Russian Empire, and subsequently with the Russian Empire. The absence of gender discrimination characterizes Ukrainian society as a whole. In modern Ukraine Yevgeniya Kononenko notices a lack of equal and equal representatives of women of masculine gender. The same thing is done by Mariyana Khrypovych and Larysa Lavrynenko, whose infinite maternal love is devoid of sexual perversion, directed at the child, not at herself. An imbalance in the social situation produces the promotion of exclusively two male images: the autocrat or the eternal infant, with the absolute preference of the latter type. This is facilitated by the Ukrainians themselves. Excessive help of mothers, wives in solving all issues, protection from problems becomes a source of infantry. With the help of the figures of Adrian, Zhenyk, Zakhar, the writer emphasizes that the parity of both sexes in the rights and duties of professional and intimate constituents of human life is the only way to overcome the crisis of masculinity of men. 


\section{Moral and Ethical Accents of Works by Yevgeniya Kononenko}

The trait that T. Shevchenko emphasized in his works is treason. A comprehensive analysis and classification of betrayal is made in the novel "Betrayal". This concept acquires different shades in the definitions of Yevgeniya Kononenko, but its negative semantics remains constant. It is worth noting the author's interpretation of betrayal at the lexical level. In the artistic texts, there is a marked gender division of this quality (feminine and masculine betrayal), age (relations between parents and children). However, even the most devastating manifestation of human nature has its limits: betrayal requires punishment, not compassion and justification. Drawing on a vivid episode from the married life of Tetiana Mayakina and Zakhar Murchenko, Kononenko raises the issue of a "culture of betrayal". The wife's betrayal of the husband turns out to be the worst crime not through a marriage oath or a marriage bed, but through a witnessinfant: the woman seems to tarnish the child with her sin, sharing her own guilt with her son. A separate type of trait of national character - selfdelusion, which directly or indirectly predetermines or becomes a consequence of previous species. In the novels "Imitation" and "Betrayal" we see the symbolic gradation of the trait-definition from the personal stage to the level of national and human. Already at the beginning of the novel, in one sentence, there is a finite range of specified quality (noticeable autoallusions and reminiscences of images, situations), which is further enlightened in the reflections and actions of the characters. Yevgeniya Kononenko appeals to the reader, provoking him to draw the right conclusion: traitors form a treacherous society and state.

The previous features are markers, innate peculiarities of Ukrainian character. Another feature of the national mentality, which is represented in the artistic images of the novels is the destruction of the heredity, the national memory, which is the "achievement" of modern Ukrainian postindustrial society. Distortion of the sacrality of the family as a priority component of the society, the stable foundation of the country causes the decline of the state, because on the basis of blood ties the life of the nation is grounded. The author sees the total/partial emigration to Western Europe or the United States as a result of material impoverishment, and therefore spiritual degradation - a total neglect of the culture of one's own people in general and language in particular. Kononenko stresses that, neglecting ethnic sources, her compatriots are getting another feature: the inferiority complex has become a marker of Ukrainians. This feature is embodied in the image of a descendant of Mariyana Hrypovych. The mother achieved her 
goal, which was primarily the well-being of the young Moldovan. She provided her son with only tangible things (money, an apartment, a prestigious job, a car, a bank account), turning him into a "eurorobot". It was Mrs. Hrypovych who showed Yurij an example of family ties. In the image of her son, Yevgeniya Kononenko reproduced the process of gradual deliberate destruction of the individual in the person, causing the national catastrophe. George-Yurij is interested in being a mom as a sponsor. Neither the life nor the death of Mariyana for a son is more valuable than an apartment in Kyiv. The emotionality of the grandfather, friends, colleagues at the funeral of the mother is amazing pragmatic Moldovanskyj. The author sees the main reason for the total leveling of ethnic nature in forgetting her native language. Yurij is fluent in four foreign languages and does not want to know Ukrainian, even though he has remained in the boy's memory. The loss of language led to the loss of personality. The language focuses on the experience of generations: it is constantly evolving, acquiring new means and forms of expression that reflect the outlook of the nation and ensure the progress of the individual. Yevgeniya Kononenko emphasizes the role and importance of ethnic identification. Yurko is Ukrainian by birthplace only. By choosing another's style of behavior, thinking and life, he lost touch with himself. An emotionally capable boy with unusual thinking disappeared under the mask of a programmed seventeen-year-old machine. In a commentary by Larysa about George-Yurij's indifference to Mariyana's life and death, the author explains this phenomenon as a result of a break with his mother. The image of the mother Yevgeniya Kononenko identifies with the fate of Ukraine, for which the problem of escape or deliberate placement of children outside the country is extremely relevant today. Instead of promoting the authority of one's own state in the world community, Ukrainians readily support and provide the mental and creative potential of America and Europe. The writer points to the role of the mentality, according to which the ethnic identity of a person and recognition of an individual nation by other communities are formed ${ }^{3}$.

Yevgeniya Kononenko revealed typological features of new Ukrainian character: total treachery, emotionalism, loss of ethnogenetic continuity in the gap of the necessary connection of generations, male infantilism, inferiority complex, supra-individualism. The writer's view is based on the objective analysis of events that take place outside the immediate visible presence of the author.

\footnotetext{
${ }^{3}$ Wollstonecraft, Mariya. A Vindication of the Rights of Woman. London: Campbell. Everyman's library, 1992. P. 206.
} 
The author highlights in the characters the main features of national character. Her reasoning is consistent with the French sociologist LeBon's conclusion that the people determine the fate of the nation. The author portrays the realities of today to prove the danger of the complete disappearance of Ukrainian, the beginning of which can be observed in the modern country. Exploring nature, human nature, the writer embodies in art images hypertrophied manifestations of established and new features of Ukrainian mentality, gender peculiarities: lack of decent male representatives and selfishness distorts maternal feelings; the destructive pressure of the patriarchal idea of the lord-breadwinner causes the loss of "related labor", which is the beginning of one's own destruction; breaking the ethnic-blood bond contributes to spiritual degradation. Changing oneself to please modern pragmatic tendencies contrary to the genetic basis of mentality has a completely natural result - imitation of life in selfdestruction as a result of total conscious self-deception. The analysis of the concepts of truth, imitation, betrayal, life, death, interconnected by the author requires an appeal to the philosophical component of Yevgeniya Kononenko's novels. The substantive core of the philosophical level of artistic texts is the dominant of existentialism, namely, the presence of a person in such a special property as the spirit. Given that a human being is free, he or she must manage her/his own destiny. Therefore, the freedom of the individual is embodied in the choice of his/her self. Each act approaches or detains a person in achieving this goal. Individual freedom becomes a way to itself - an existence, a "real existence". The temptation to find one's essence is the temptation to emulate the majority, the behavior of the crowd. In the novels "Imitation" and "Betrayal", the variants of manifestations of imitation are represented from real (emerald in the heel, which, it seems, cannot be tampered with) to universal philosophical ones. When man begins to act, focusing only on the thoughts of others, without having his own position, he loses himself. After all, the external "invalid being", that is, the generally accepted norms of a certain social order, which are manifested in religious dogmas or behavioral rules, are often incompatible with the freedom granted from birth. Thus, the image of Dmytro Stebelko reproduces the effect of gender stereotypes, which ultimately collapse for the sake of existence. Fear of ridicule and scorn by the social masses can paralyze the will of the individual, condemning him to exist instead of a diverse life. This impasse, the inner hopelessness, causes a conscious escape from oneself, because the desire to become "like everyone" makes it impossible to graduate to the level of personality. 
Imitation means betrayal of its uniqueness, which leads to the elimination of the criterion of responsibility - the indicator of personality. But the question of betrayal remains in the sphere of free choice of man, therefore, betrayal is also a category of freedom, as evidenced by the words from the epigraph to the novel "Betrayal" (Oksana Samara's poem): "What is betrayal? Everything in the world is treason ...". The choice of betraying one's self or the rule created by others depends on the true existence of a person, his or her development from an individual, one of many, to a unique personality.

Yevgeniya Kononenko explains betrayal as a litmus test, checking a person himself. The choice of betrayal is closely linked to the search for one's own truth, which determines the purpose of being, probably, the death of the individual. The writer portrays how, under the influence of external circumstances, an individual can consciously neglect a true "I". The main obstacle is the fear of a full-fledged life, which is forced to make choices every time, while bringing a person closer to the existence that he uses every second to discover his own uniqueness and to build up to the level of personality.

In the image of Mariyana Hrypovych, the gradual path of a person is embodied from a self-created, partly imposed from the outside, role-mask to natural authenticity, to peace with his being. For Mariyana, the truth of her "I", of true existence, was love. Veronica Rajewski's play "The Road to Betrayal" (which is an auto-allusion in Yevgeniya Kononenko's novel "Betrayal") embodies the spectrum of doubts and fears of each person. Not to imitate means not to betray your own "I". Facelessness, the merging of the individual with the mass, the same fear of being responsible for one's own actions ${ }^{4}$. In describing the progress of the heroes, the writer emphasizes that it is worth the risk and develop for the sake of the chosen personal truth, which will ensure the existence of existence - to be oneself.

In the artistic texts of Yevgeniya Kononenko there is a symbolism of titles that become famous during the interpretation of events in the novels "Imitation" and "Betrayal". For example, by the names of the villages used by the writer, one can recreate the historical past of the country and see in it its present. The Friendly Motherland forces to remember the times of the Soviet regime, when all and all obeyed orders from above. The consequences of the Communist Party's activities were repression, forced collectivization, collective labor, the destruction of rights to private

\footnotetext{
${ }^{4}$ Кононенко С. Зрада. Львів: Кальварія, 2002. Ст. 74.
} 
land, and, first of all, Russification with the elimination of national customs. Attracting certain village names, Kononenko represents a distortion of one of the ancient traditions. It was a common custom in Ukraine to give the names of the locals to the inhabitants and owners of these ancient lands. The territory was named after a definite indicator: historical, etymological, due to the peculiarities of the population of the locality or of the dominant species of plants, birds, fish, animals, or the mention of a bright event, which later became a legend. The totalitarian system has established its names to eradicate sources and cells of national memory. Due to the Cold War, the Soviet authorities were forced to seek ways to co-operate with the countries of the world by organizing numerous strictly regulated youth festivals that took place under the slogan "Friendship of Peoples". This hypocritical motto was promoted to demonstrate the apparent joy of Soviet people who no longer belonged to their own ethnic community, did not know respect for their nation. The Soviet people "sincerely" made friends with the Cubans, Germans, Chinese, French and more. The name of the village -"Druzhbonarodivka"- testifies to the absurdity of the actions, the perverted interference of the totalitarian regime in the lives of the people (to recall at least the onomastic).

If "Druzhbonarodivka" prompts an excursion into the old nightmares of the socialist past, the name of the neighboring village stands as a marker of modern Ukraine. Kubov treats money as being of the highest value. Luxury fans are the whole family of "businessman". Wealth eliminates the need for human communication between husband and wife, parents and children, grandparents. It is easier and more enjoyable for small family members to talk on the mobile phone while in a home that is too big. In creating the image of Kolya Kubov, Yevgeniya Kononenko used a contrast technique: Lincoln for trips to villages and flavored water for finger washing combined with perfect knowledge of brutal swearing, criminal laws of cooperation, which testifies to the outright savagery of the "new Ukrainians", a cultural limitation as opposed to property wealth. The loss of humanity is not only characteristic of a flock of "authorities". Massive material impoverishment spreads indifference among ordinary people. The writer points out that the state neglects the urgent need to revive the village, the ethnic source of the Ukrainian nation, causing the spiritual and physical extinction of its citizens.

Yevgeniya Kononenko proves the validity of this reasoning with several strokes: murder for the sake of twenty gryvnya, rats at school, 
crippled children who are carried away from despair by their parents to ask alms, despair of mother who cannot feed daughter and son, sad eyes and tears peers.

In the novels "Imitation" and "Betrayal" the problem of human impairment is a cross-cutting theme. Children, the elderly, the sick, as well as those who could not timely navigate the rules of survival of the modern day are beyond the interests of the country in which they live. In addition to the social-economic indicator of living standards, the realization of creative and mental potential is the world status criterion of the country: talent and smart in Ukraine are mostly devoid of state support. The search for scholarships for the Maryana Hrypovych Foundation is an "empirically empirical" journey to the most deprived regions. Therefore, the constant emigration of young people does not seem strange. During Ukraine's stay in different countries, supplying Ukrainians - athletes, artists, scientists, voluntary or forced, to other countries was the norm. Independence gained indicated that the state did not understand the weight of those extraordinary individuals who secure the status of the country, representing it in the world.

Yevgeniya Kononenko stresses the issue of the value of a work of art, its importance for national culture: honoring art is a pledge of the wellbeing of the country, and the development of aesthetic taste is directly proportional to the progress of individuality. The author highlights the urgent problem of urgent support of the basic branches of human activity - science, education, culture, since it is difficult for units to save the whole nation from spiritual decline. The fate of a talented person in modern Ukraine, which could not be realized through moral principles and went unnoticed among the many misfortunes, is vividly reproduced in the image of Anatolij Sumczov. Playing the Underground is a "proper" evaluation of a virtuoso violinist who has retained his personality for the sake of a few able-bodied rural music school students. Due to such single cases, when a person realizes his or her duty without the patronage of the powerful, Ukraine remains not only on the geopolitical but also on the cultural map of the world. The writer points out that the issue of loss of national consciousness and ethnic identification becomes extremely dangerous due to the inactivity of the state. The problem of the devaluation of human life is central to the artistic texts of Yevgeniya Kononenko, since its resolution can overcome both the material and the spiritual crisis of Ukrainian society ${ }^{5}$.

\footnotetext{
${ }^{5}$ Гендер і культура :збірник статей /упоряд. В. Агеєва. Київ : Факт, 2001. Ст. 220.
} 
There are many mystical elements used in the novels "Imitation" and "Betrayal”. For example, the clock in Mariyana Hrypovych's apartment stopped the moment his owner died; telepathic communication between people (the appearance of anxiety in Sashko Ryzhenko for Mariyana); the curse of Mariya Stebelko of her husband, who has died in the year of the accident. The constant meetings of Larysa Lavrynenko with her unnoticed boy (on the bus, at the train station, in the cafe), who will eventually prove to be the killer of her girlfriend or crossing through the mutual acquaintances of Veronica Rayevskay and Kateryna Rachko wife and mistress, can prove the right idea. The most fatal, however, symbolic coincidence is embodied in the fate of Mariyana Hrypovych. Yurij-George Moldanskij, son, is a seventeen-year-old young man, financially well-off, educated abroad, and entered one of the finest universities in Western Europe. He is a pragmatic, emotionally deprived person with a vital material orientation that determines a young man's thoughts and behavior. Instead, Yurko Podgubny, the murderer of Mariyana Hrypovych, is a twelve-year-old boy who can do anything to protect and help his family, a mother who lacks money even for food. The impetus for the crime was not ambition or money, but disdain, insult to the sick sister, loss of the only opportunity to receive money for her treatment and anger at own infirmity. The coincidence of the names of Mariyana's son and her murderer is not accidental. Yurko Podgubny appears as a reflection of Yurij Moldansky at the same age, that is, before traveling, as it turned out to be a life-long emigration, abroad. The boys are characterized by common traits: ingenuity, tenderness, dreaminess. They were both born in Ukraine but grew up under different conditions. The European machine for the production of robots contributed to the destruction of the inborn traits in Yurij Moldansky. Yurko Podgubny is rid of them because of the total impasse created by the authorities of his country, in which social circumstances lead to the destruction of ethical principles. The main thing that brings the two Yurij together is Mariyana's death. Both boys are indirectly and directly murderers of Ms. Hrypovych, although the perpetrator of the crime is largely the woman herself. Yurko Podgubny destroys Mariyana physically, pushing her under the train. The reasons for such a terrible act can be found in the words of a teenager. However, Yurij-George will contribute to the disappearance of his mother as a whole. All things, except those with the least material value, will end up in the landfill, family photo albums will be burned immediately. If Yurko commits a crime of affection, then 
Yurij deliberately does so. An adult, the only descendant of the Hrypovych-Moldanskij family, destroys the memory, the ethnogenetic connection of generations of past, present and future.

In the works of Yevgeniya Kononenko there is an irony and no pathos and moralistic directions, despite the importance of the problems raised. The philosophical comprehension of universal questions is embodied in artistic images, in the thoughts, actions and destinies of which the totality of dreams, hopes, fears, doubts and contradictions of each person is reproduced. Her texts are a synthesis of genre types of the novel: the criminal plot with the image of a scammer points to a detective; actualization of the issues of the present (employment in the West, depreciation of work in the scientific field and culture, in the medical field), daily worries, office and home conversations,a picture of the life of an individual family reveals the features of a social novel; the author's emphasis on the intrinsic motivation of the character's behavior, attention to the role of gender stereotypes and traits of national mentality determine the presence of elements of the psychological component; assigning central status to the categories of "life" and "death", carefully examining the concepts of "betrayal" and "imitation",Kononenko emphasizes the superiority of the deep philosophical primordium in her novels over the external presentation of events. Neglect of at least one component will lead to a distorted perception and an incorrect interpretation of the artistic text ${ }^{6}$.

The focus of Yevgeniya is the person, theattitude to the world and life, the search for own self through the freedom of choice, a certain purpose, which is self-identification. Society acts as a factor that helps or hinders the individual to achieve subsistence, to gradualize to a level of personality that seeks to be fully realized in the intimate and professional spheres of human being.

\section{CONCLUSIONS}

Yevgeniya Kononenko represents the features of feminine writing. First of all, it is worth noting the character formation. The writer creates an artistic image gradually, throughout the text with the help of skillful dialogues and monologues, retrospectives, where the criminal history provides attention to each figure through the end goal - exposing the crime. Detective history in the novels "Imitation" and "Betrayal" is not the dominant of the works. The artistic texts are characterized by the

\footnotetext{
${ }^{6}$ Oates, Joyce Carol. (Women) Writer: Occasionsand Opportunities. New York: A William Abrahams book, 1989. P. 278.
} 
priority of psychological and philosophical components. The author strives to reveal the root causes of external and internal collisions. In addition, the writer emphasizes the credibility of the portrayed because of the authenticity of artistic images and situations. In this way, Yevgeniya Kononenko emphasizes the universality of the problems raised in the novels. Using a crime story that initially captivates the reader, the writer confesses that she is a fascinating intrigue. From here, one can interpret the influence of the conscious and the unconscious on the actions of the characters when the marginal and major problems become interchangeable in certain situations. This position of the female author defines the content specificity of the novels: through personal coverage of the national and universal. Kononenko strives to embrace a holistic picture of life in modern Ukraine. The writer not only actualises the material problems of the inhabitants of her country, but also tries to recreate the spiritual atmosphere of the Ukrainian society through the feelings and reflections embodied in the artistic images of the novels.

Mosaic integrity is the intersection of thoughts and destinies, which causes fragmentation of construction. Multilevel structure of works, analysis of the whole semantic spectrum of concepts of "imitation" and "betrayal", from the material to the spiritual, from the personal individual to the national, universal, illuminates and provides the multifaceted artistic texts, their semantic multiplicity, which is facilitated by open finals.

\section{SUMMARY}

The article devotes to the the analysis of the prose of Yevgeniya Kononenko. Attention focuses on detective stories. Writer determines the problem-thematic circle, reveals the secrets of the creative laboratory of the artist, sets her own moral and ethical priorities, accents the main ideological orientations, attracts prototype images, presents the Motherland's vision. In this way, the reader is co-author, who continues to reflect during and after the reading of artistic text.

The work highlights the main figurative-expressive means and features of the textual organization of the work (symbol, stream of consciousness, excursion, anticipation, refrain, open final), investigates author's idiostyle. 


\section{REFERENCES}

1. Біла А. Сфери інобуття у прозі Свгенії Кононенко // Березіль, 2001. - № 3-4. С. 56-58.

2. Гендер і культура: збірник статей / упоряд. В. Агеєва. Київ : Факт, 2001. 223 c.

3. Кононенко С. Імітація. Львів: Кальварія, 2001. 188 с.

4. Кононенко С. Зрада. Львів: Кальварія, 2002. 160 с.

5. Oates, JoyceCarol. (Women) Writer: Occasionsand Opportunities. NewYork: A William Abrahams book, 1989. 401 p.

6. Wollstonecraft, Mariya. A Vindication of the Rights of Woman. London: Campbell. Everyman’s library, 1992. 213 p.

\section{Information about the author:} Tkachenko T. I.,

Doctor of Philology, Associate Professor at the Department of Slovenian Philology and Journalism, Academic and Scientific Institute of Philology and Journalism,

V.I. Vernadskiy Taurida National University 33, J. McCain str., Kyiv, 01042, Ukraine 